\title{
Neglected Pulmonary Arterial Hypertension in Sickle Cell Anaemia during Prenatal Care
}

\author{
Minoodokht Bavarsad Karimi \\ Department of Gynecology, Iran University of Medical Sciences, Tehran, Iran
}

Received: 29/01/2020

Accepted: $18 / 02 / 2020$

Published: 08/04/2020

How to cite this article: Karimi MB. Neglected pulmonary arterial hypertension in sickle cell anaemia during prenatal care. EJCRIM 2020;7: doi:10.12890/2020_001532.

Conflicts of Interests: The Authors declare that there are no competing interests.

This article is licensed under a Commons Attribution Non-Commercial 4.0 License

\section{ABSTRACT}

Pulmonary arterial hypertension (PAH) is one of the main complications of sickle cell disease (SCD) and imparts significant risk during pregnancy. Here, we report the outcome of undetected PAH in a pregnant woman with SCD. The patient presented with severe progressive dyspnoea with echocardiographic findings of high pressure in the pulmonary artery in the 37th week of pregnancy. Despite an emergency caesarean section, both mother and neonate died. Regular cardiovascular check-up is essential for SCD patients and careful prenatal care should include cardiovascular evaluation. $\mathrm{PAH}$ during pregnancy is associated with high mortality and morbidity. As there is no proof that new advanced therapies decrease the risks, early diagnosis in pregnant patients with underlying disease, like sickle cell anaemia, is essential and termination of pregnancy should be considered.

\section{LEARNING POINTS}

- Cardiovascular echocardiography and careful prenatal care are essential in patients with sickle cell disease.

- Research results should be applied to clinical practice to improve outcomes for patients with sickle cell disease.

\section{KEYWORDS}

Pregnancy, pulmonary hypertension, sickle cell anaemia, prenatal care

\section{INTRODUCTION}

Sickle cell disease (SCD) is a haemoglobinopathy typically inherited in an autosomal recessive pattern and results in repeated vaso-occlusive crises that severely affect multiple organs ${ }^{[1]}$. The most common type of SCD is sickle cell anaemia (SCA). In female patients, the underlying anaemia, non-inflammatory vasculopathy and multi-organ dysfunction, including cardiomyopathy and pulmonary arterial hypertension (PAH), complicate pregnancy and delivery, contributing to high morbidity and mortality for both mother and fetus. Pregnancy-related physiological changes increase the clinical risk in SCD women. These patients are at greater risk of gestational hypertension and preeclampsia, eclampsia, abruption, antepartum bleeding, preterm labour and fetal growth restriction. Consequently, close medical care and treatment is essential in such patients ${ }^{[2]}$.

Pregnancy was contraindicated for SCD patients in the past, but recent advances in the diagnosis and treatment of disease complications during pregnancy have been associated with more favourable outcomes and an increase in the number of women proceeding with pregnancy $^{[3]}$. Because this disease is relatively rare, prenatal care needs may be neglected, especially by health workers in local (public) health centres. Here we describe the case of a pregnant woman with SCA and a missed diagnosis of PAH. 


\section{CASE DESCRIPTION}

A 35-year-old pregnant woman with SCA was admitted to our hospital (Abolfazl Hospital, Minab, Hormozgan, Iran) with a 37-week 4-day pregnancy and a 4-day history of shortness of breath. The last menstrual period was on 28 April 2016. The expected date of confinement was 11 October 2016. The patient had had three previous pregnancies, resulting in one female child from her first pregnancy who died at the age of 2 from an unknown cause, and two children who were delivered by caesarean section (C-section) and were still alive. One week before presentation, the patient had been admitted by an internal medicine specialist with dyspnoea and severe anaemia (Hb 6.5). She had been transfused with of 1 unit of packed red blood cells (RBCs) and discharged without seeing a cardiologist.

On arrival, the patient had a pulse of $128 / \mathrm{min}$, a respiratory rate of $36 / \mathrm{min}$, blood pressure of $130 / 90 \mathrm{mmHg}$, and a temperature of $36^{\circ} \mathrm{C}$. The rest of the physical examination was unremarkable.

Echocardiographic finding were as follows: left ventricular ejection fraction 55\%, D-shaped left ventricle in systole and diastole, mild to moderate tricuspid regurgitation, a tricuspid regurgitation gradient of $55 \mathrm{mHg}$, and a systolic pulmonary atrial pressure of $68 \mathrm{mmHg}$, indicating severe PAH. Urine dipstick protein tests 1 week before admission and at presentation showed progressive $\geq 2$ proteinuria. Laboratory findings were as follows: severe leucocytosis, with a white blood cell count of $95,000 / \mu l$, platelet count of $142,000 / \mu l$, and haemoglobin of $6.5 \mathrm{~g} / \mathrm{dl}$.

The patient was admitted to the intensive care unit. The dyspnoea worsened considerably during hospitalization. The patient underwent an emergency C-section because of a significant decline in the fetal heart rate. The female newborn had low Apgar scores at both 1 and 5 minutes and died after a few hours. The mother experienced a respiratory cardiac arrest during the C-section and died despite 20-25 minutes of resuscitation.

\section{DISCUSSION}

This report describes missed PAH in a pregnant woman with SCA, emphasizing the need for careful prenatal examination including cardiovascular investigation in such patients. If our patient had received the appropriate prenatal care mandated by her underlying disease, her death could have been prevented by a legal abortion.

SCD is a vasculopathic disorder which damages multiple organs and the cardiopulmonary system. Many SCD complications worsen during pregnancy ${ }^{[4]}$. The results of a study of a large cohort of nearly 4,400 deliveries over 3 years revealed multiple antepartum admissions due to disease-related complications such as acute chest crises, pain crises, symptomatic anaemia and infections, longer hospital stays, and higher rates of intrauterine growth restriction that were independently associated with $S C D^{[3]}$. Adverse pregnancy outcomes in $S C D$ women were high during the 1970s, and doctors advised strongly against pregnancy ${ }^{[5]}$. However, the maternal death rate has been reduced to less than $2 \%$ in recent years ${ }^{[6]}$. Consequently, the rarity of the disease, and the small proportion of SCD women who are able or willing to become pregnant, may have resulted in low awareness among health staff of the need for specific prenatal care.

PAH is a main cause of death in SCD patients, having a prevalence of 20-40\% and a high 2-year mortality rate. Therefore, all SCD patients, especially pregnant women, should be screened regularly with transthoracic Doppler echocardiography to estimate pulmonary artery pressures and cardiac output ${ }^{[7]}$. Heart failure caused by PAH should also be considered in pregnant patients ${ }^{[3]}$. PAH is directly associated with chronic haemolytic anaemia. Haemolysis and the consequent release of haemoglobin from RBCs increases the consumption of nitric oxide (NO) and the released arginase reduces the production of NO. Nitric oxide is a potent vasodilator and a critical regulator of vascular homeostasis. Its reduction is thus associated with vasoconstriction and proliferative vasculopathy that results in $\mathrm{PAH}^{[7,8]}$. Moreover, recurrent episodes of acute chest syndrome that typically occur in $40 \%$ of patients and cause restrictive chronic lung disease, are another possible cause of PAH. PAH may remain undetected until the disease is advanced ${ }^{[9]}$.

Pregnant women with SCD should be supplemented with $4 \mathrm{mg}$ daily of folic acid to support rapid RBC turn-over ${ }^{[10]}$. Red cell exchange transfusion and hydroxyurea that may contribute to an increase in fetal haemoglobin levels are recommended for those with organ dysfunction; however, data on the use of hydroxyurea during pregnancy are lacking. Sildenafil, which potentiates the effect of NO, is used for SCD-related PAH ${ }^{[11]}$. Limited data show that sildenafil is safe in pregnant women ${ }^{[12]}$, and therefore, as untreated PAH is a real threat for both mother and fetus, its use outweighs the risks. 


\section{REFERENCES}

1. Rees DC, Williams TN, Gladwin MT. Sickle-cell disease. Lancet 2010;376(9757):2018-2031.

2. Boulet SL, Okoroh EM, Azonobi I, Grant A, Hooper WC. Sickle cell disease in pregnancy: maternal complications in a Medicaid-enrolled population. Matern Child Health J 2013;17(2):200-207.

3. Chakravarty EF, Khanna D, Chung L. Pregnancy outcomes in systemic sclerosis, primary pulmonary hypertension, and sickle cell disease. Obstet Gynecol 2008;111(4):927.

4. Dauphin-McKenzie N, Gilles JM, Jacques E, Harrington T. Sickle cell anemia in the female patient. Obstet Gynecol Surv 2006;61(5):343-352.

5. Fort AT, Morrison JC, Berreras L, Diggs LW, Fish SA. Counseling the patient with sickle cell disease about reproduction: pregnancy outcome does not justify the maternal risk! Am J Obstet Gynecol 1971;111(3):324-327.

6. Hassell K. Pregnancy and sickle cell disease. Hematol Oncol Clin N Am 2005;19(5):903-916.

7. Lin E, Rodgers G, Gladwin M. Hemolytic anemia-associated pulmonary hypertension in sickle cell disease. Curr Hematol Rep 2005;4(2):117-125.

8. Jison ML, Gladwin MT. Hemolytic anemia-associated pulmonary hypertension of sickle cell disease and the nitric oxide/arginine pathway. Am J Respir Crit Care Med 2003;168(1):3-4.

9. Van Enk A, Visschers G, Jansen W, Statius van Eps L. Maternal death due to sickle cell chronic lung disease. Br J Obstet Gynaecol 1992;99(2):162-163.

10. Cunningham F, Leveno K, Bloom S, Spong CY, Dashe J. Williams Obstetrics, 24e. New York: McGraw-Hill Education; 2014.

11. Veille J-C, Hanson R. Left ventricular systolic and diastolic function in pregnant patients with sickle cell disease. Am J Obstet Gynecol 1994;170(1):107-110.

12. Dunn L, Greer R, Flenady V, Kumar S. Sildenafil in pregnancy: a systematic review of maternal tolerance and obstetric and perinatal outcomes. Fetal Diagn Ther 2017;41(2):8188. 